\title{
PENGGUNAAN APLIKASI GEOGEBRA DALAM PEMBELAJARAN MATEMATIKA DI SEKOLAH MENENGAH PERTAMA
}

\author{
Andri Rahadyan'), Purni Munah Hartuti' ${ }^{2)}$, Aulia Ar Rakhman Awaludin ${ }^{3)}$ \\ Program Studi Informatika, FTIK, Universitas Indraprasta PGRI \\ arahadyan.tinformatika.unindra@gmail.com ${ }^{1)}$, purniibunyahanum@yahoo.co.id ${ }^{2)}$, \\ aulia_awaludin@yahoo.co.id ${ }^{3)}$
}

\begin{abstract}
Abstrak
Diperoleh data bahwa penggunaan komputer dalam pembelajaran mayoritas baru sebatas penggunaan powerpoint. Guru-guru matematika masih menghadapi kesulitan dalam pembuatan media pembelajaran dan bahan ajar. Solusi yang ditawarkan adalah dengan memberikan pelatihan aplikasi GeoGebra kepada guru-guru matematika untuk membantu mereka dalam proses pembelajaran matematika. Tujuan kegiatan ini adalah meningkatkan pemahaman guru tentang peranan media pembelajaran matematika dan meningkatkan pengetahuan dan keterampilan guru tentang media pembelajaran virtual (mathlet) yang baik dan eksploratif. Metode yang akan dilakukan dalam kegiatan ini adalah melalui beberapa tahap, yaitu observasi langsung, wawancara, presentasi, dan tanya jawab. Hasil dari kegiatan ini adalah guru dapat meningkatkan kualitas proses pembelajaran sesuai dengan ilmu yang diperoleh dalam pelatihan, guru lebih kreatif dan inovatif dalam menciptakan proses pembelajaran, guru memiliki pemahaman dan pengetahuan tentang media pembelajaran virtual, guru dapat menggunakan aplikasi GeoGebra untuk membuat media pembelajaran virtual, guru dapat membuat media visual, bahan ajar, dan instrumen penilaian yang berkaitan dengan materi aljabar dan geometri.
\end{abstract}

Kata Kunci: GeoGebra, matematika, konstruktivisme, mathlet

\begin{abstract}
It is found that the beneficials of computers in mathematics learnings are just limited in using powerpoint so that the teachers still have difficulties in making learning media, teaching materials, and the assessments. The solution is by providing GeoGebra application training to the teachers to help them in the learning process of mathematics based on constructivism. The objectives of this activity are to improve teachers' understanding of the role of learning media in general in math learning, to improve teachers' knowledge of good virtual learning media (mathlet), to improve teachers' skill in using GeoGebra to create virtual math learning media, and to increase teacher's knowledge and skill in create an explorative mathlet. The methods in this activity are direct observation, interviews, presentations, and frequently asked questions. The results of this activity are the teachers can improve the quality of the learning process, the more creative and innovative teachers in creating the learning process, the teachers have the understanding and knowledge of virtual learning media, the teachers can use GeoGebra application to create virtual learning media, teaching materials, and the assessment instruments.
\end{abstract}

Keywords: GeoGebra, mathematics, constructivism, mathlet 


\section{PENDAHULUAN}

Perkembangan teknologi informasi yang semakin maju menuntut setiap individu untuk selalu beradaptasi dengan perkembangan zaman. Manfaat teknologi informasi dalam perkembangan kehidupan sehari-hari memang sangat banyak, terutama untuk pendidikan, industri, internet, dan berbagai bisnis dan bidang lainnya. Perkembangan teknologi informasi telah mendorong para insan pendidikan untuk memanfaatkannya dalam bidang pendidikan. Perkembangan informasi saat ini memunculkan harapan yang dapat meningkatkan daya minat anak-anak untuk belajar yang berawal pada usia dini. Hal tersebut didukung oleh pernyataan Pranasiwi, dkk (2015) bahwa tuntutan zaman mewajibkan anak-anak mengenal teknologi sejak dini dan tepat guna. Dalam peningkatan daya minat anak untuk belajar maka seorang guru harus mempunyai daya kreativitas dan inovasi dalam penyajian pembelajaran di kelas dengan menggunakan media pembelajaran yang berbasis Teknologi Informasi dan Komunikasi. Sumber informasi tidak lagi terfokus pada pembelajaran konvensional seperti teks dari buku, tetapi lebih luas dari itu.

Teknologi Informasi dan Komunikasi, khususnya komputer, dewasa ini memiliki peran yang semakin besar dalam proses pendidikan. Kualitas pendidikan dewasa ini sangat membutuhkan peran sentral komputer. Dalam beberapa tahun terakhir, Kementerian Pendidikan Nasional tak henti-hentinya mengampanyekan pemanfaatan teknologi dalam pembelajaran. Pembaharuan dalam pendidikan telah dilakukan di berbagai negara. Pembaharuan itu selalu melibatkan pemanfaatan teknologi yang menjadi bagian integral dari pembaharuan pembelajaran. Perubahan sangat deras yang terjadi adalah perubahan dalam hal pemanfaatan komputer untuk menggerakkan dan memungkinkan apa yang sebelumnya tidak mungkin terjadi dalam pembelajaran. Jika dirancang dengan baik, komputer bisa diprogram sedemikian rupa sehingga menghasilkan media pembelajaran virtual untuk menggerakkan pembelajaran berkualitas, khususnya eksplorasi yang sangat tinggi. Pemanfaatan komputer juga memungkinkan pembelajaran untuk membahas hal-hal yang sebelumnya tidak mungkin, seperti materi kalkulus yang intensif, simulasi proses berskala mikro maupun makro, dan penelusuran keterkaitan antarparameter dalam suatu persamaan matematika.

Bagaimana dengan pembelajaran matematika di SMPN 155 Jakarta dan SMP Uswatun? Sekolah-sekolah ini relatif dekat dengan kota sehingga komputer dan sarana-sarana pendukungnya tersedia secara cukup memadai. Berdasarkan diskusi dengan beberapa guru matematika di kedua sekolah tersebut pemanfaatan teknologi dalam pem-belajaran matematika, diperoleh data bahwa pemanfaatan komputer dalam pembelajaran baru pada sebatas peng-gunaan powerpoint, termasuk di sekolah-sekolah favorit. Penggunaan ini pun masih sangat minim kuantitasnya, khususnya pada pembelajaran matematika. Mereka terkadang lebih nyaman mengajar hanya dengan menggunakan spidol dan papan tulis. Mereka merasa pembelajaran matematika dengan powerpoint menjadikan pembelajaran menjadi kaku dan siswa tidak mengetahui atau mengalami proses untuk mendapatkan apa yang tertera pada layar. Terkait dengan pembelajaran yang memerlukan ilustrasi grafik, baik dalam pembelajaran aljabar maupun geometri, guru jarang menggunakan komputer, sebagian besar penjelasan materi dipresentasikan dengan spidol 
dan papan tulis. Representasi grafik di papan tulis tentu saja bersifat statis, sehingga peranan sebuah parameter (koefisien) dari sebuah persamaan matematika tidak bisa dieksplorasi dengan bebas. Akibatnya pengaruh koefisien tersebut terhadap grafik dari persamaan tadi sulit dipahami siswa. Tidak demikian halnya dengan grafik yang direpresentasikan dengan bantuan komputer. Grafik sajian komputer bisa sangat dinamik, perubahan pada suatu parameter dari suatu persamaan akan secara instan mengubah tampilan grafik dari persamaan tersebut. Dengan cara ini, keterkaitan antara persamaan dan grafiknya dengan sangat jelas bisa terlihat. Namun sayangnya, tidak banyak guru yang memiliki kemampuan membuat visualisasi grafik dinamik dengan bantuan komputer seperti ini.

Berdasarkan hasil di atas, tampak bahwa guru-guru matematika SMP masih menghadapi kesulitan terkait dengan pembuatan media pembelajaran matematika dan bahan ajar. Oleh karena itu, perlu suatu kegiatan pelatihan program aplikasi yang dapat memecahkan permasalahan di atas. GeoGebra adalah salah satu program aplikasi yang bisa dimanfaatkan untuk mengatasi masalah tersebut.

GeoGebra adalah suatu software pembelajaran yang dikembangkan oleh Markus Hohenwarter et all (2008) untuk pembelajaran matematika di sekolahsekolah. GeoGebra adalah freeware sehingga dapat diunduh di internet dengan berlisensi gratis.

Sesuai dengan namanya yang merupakan gabungan dari geometry dan algebra, software ini bisa dimanfaatkan untuk membuat konsep-konsep matematika menjadi dinamik. Konstruksi dan eksplorasi dari bangunbangun geometri dan grafik suatu persamaan semuanya dapat dilakukan secara dinamik, sehingga pembelajaran matematika menjadi eksploratif di mana siswa bisa melihat secara langsung dan instan keterkaitan antara representasi analitik dan visual suatu konsep maupun keterkaitan antar konsep-konsep matematika.

Pembelajaran matematika seharusnya menggunakan sedikitnya 3 pendekatan, yaitu analitik, visual, dan numerik. Hal ini dengan sangat baik terakomodasi dalam GeoGebra. Tidak mengherankan bila sejak dirilis, mulai tahun 2002 hingga 2010 software ini telah mendapat sekitar 12 penghargaan internasional yang semuanya memosisikan GeoGebra sebagai software pendidikan terbaik, di antaranya National Technology Leader Award, Laureat in the Education Category, best project for educator dan lain-lain.

Berdasarkan hasil analisis yang dilakukan oleh tim pengabdian masyarakat, maka beberapa permasalahan yang dihadapi oleh SMP Negeri 155 Jakarta dan SMP Uswatun Hasanah di antaranya:

1. Guru masih kesulitan dalam membuat media visual yang melibatkan gambar geometri maupun grafik suatu persamaan karena keterbatasan penguasaan software yang relevan.

2. Guru masih mengalami kesulitan dalam membuat bahan ajar terutama yang berkaitan dengan materi gambar geometri.

3. Guru masih mengalami kesulitan dalam instrumen penilaian matematika terutama yang berkaitan dengan materi gambar geometri.

4. Kurangnya media pendukung yang dimiliki guru maupun sekolah untuk pengembangan kualitas pembelajaran di sekolah.

Sebelum melakukan kegiatan pengabdian masyarakat, tim dosen terlebih dahulu melakukan riset tentang beberapa permasalahan yang dihadapi 
oleh mitra (SMP Negeri 155 Jakarta dan SMP Uswatun Hasanah Jakarta). Metode yang dipakai adalah pengamatan secara langsung dan melakukan kegiatan wawancara. Dari hasil pengamatan yang dilakukan oleh tim dosen, maka dipilih permasalahan yang dihadapi oleh para guru, yaitu guru masih mengalami kesulitan dalam membuat media visual, bahan ajar dan instrumen penilaian mengenai materi yang berkaitan dengan aljabar dan geometri dikarenakan kurangnya media pendukung yang dimiliki guru dalam membuat instrumen.

Solusi yang ditawarkan oleh tim dosen dalam melakukan pengabdian masyarakat ini adalah dengan cara memberikan pelatihan aplikasi GeoGebra kepada guru-guru Matematika di SMP Negeri 155 Jakarta dan SMP Uswatun Hasanah Jakarta untuk membantu guru dalam proses pembelajaran matematika berbasis konstruktivisme. Adanya pelatihan ini diharapkan dapat meningkatkan kemampuan tenaga pengajar dalam mengembangkan media visual, bahan ajar dan instrumen penilaian di sekolah. Adapun prosedur yang dilakukan tim dosen dalam melakukan pelatihan bagi tenaga pengajar SMP Negeri 155 Jakarta dan SMP Uswatun Hasanah ialah:

1. Menyiapkan materi dan program untuk pelatihan.

2. Menyiapkan desain pelatihan bagi guru.

3. Menyiapkan sarana untuk pelatihan.

4. Evaluasi dan analisis hasil kegiatan pelatihan.

Terkait kegiatan pengabdian masyarakat yang akan dilakukan oleh tim dosen, kedua mitra (155 Jakarta dan SMP Uswatun Hasanah) menyambut baik dan mengapresiasi sangat positif dengan adanya kegiatan tersebut. Beberapa bentuk dukungan yang diberikan oleh mitra di antaranya:
1. Mendata dan menginformasikan kepada guru-guru yang akan mengikuti pelatihan tersebut.

2. Menyiapkan jadwal untuk tempat dan waktu pelaksanaan kegiatan pelatihan.

3. Memberikan bantuan berupa sarana dan prasarana dalam melakukan kegiatan pelatihan. berikut:

Tujuan kegiatan ini adalah sebagai

1. Meningkatkan pemahaman guru tentang peranan media pembelajaran pada umumnya dalam pembelajaran matematika,

2. Meningkatkan pengetahuan guru tentang media pembelajaran virtual (mathlet) yang baik,

3. Meningkatkan keterampilan guru dalam menggunakan GeoGebra untuk membuat media pembelajaran matematika virtual,

4. Meningkatkan pengetahuan dan keterampilan guru dalam membuat mathlet yang eksploratif.

Belajar menurut teori konstruktivisme adalah suatu proses pembentukan pengetahuan yang dilakukan oleh peserta didik sendiri (Asri Budiningsih, 2004: 58-59). Dengan kata lain, siswa harus aktif melakukan kegiatan, aktif berpikir, menyusun konsep dan memberi makna sesuatu yang dipelajarinya. Karena pengetahuan tidak dapat diperoleh secara pasif. Oleh karena itu para guru, perancang pembelajaran, dan pengembang programprogram pembelajaran ini berperan untuk menciptakan lingkungan yang memungkinkan terjadinya belajar. Artinya mereka perlu mengatur lingkungan agar peserta didik termotivasi untuk belajar menemukan pengetahuannya sendiri.

Pembelajaran hendaknya dikemas menjadi proses 'mengonstruksi' bukan 'menerima' pe-ngetahuan. Dalam proses pembelajaran, siswa membangun sendiri 
pengetahuan mereka melalui keterlibatan aktif dalam proses belajar mengajar. Siswa menjadi pusat kegiatan, bukan guru. Pem-belajaran dirancang dalam bentuk siswa bekerja, mendemonstrasikan, menemu-kan rumus, dan sebagainya.

Berdasarkan beberapa pendapat tersebut penulis menyimpulkan bahwa belajar adalah kegiatan aktif yang dilakukan oleh siswa untuk membangun pengetahuan sendiri dengan cara melakukan penemuan-penemuan baru akibat adanya interaksi secara terus menerus.

GeoGebra adalah software matematika dinamik untuk pembelajaran matematika di sekolah. GeoGebra dapat digunakan baik untuk menyelesaikan masalah-masalah matematika maupun untuk membuat media pembelajaran virtual atau menggambar bangunbangun geometrik dan grafik fungsi. GeoGebra dikembangkan oleh Markus Hohenwarter pada tahun 2001. Menurut Hohenwarter (2008), GeoGebra adalah program komputer untuk membelajarkan matematika khususnya geometri dan aljabar. Berikut adalah tampilan dari GeoGebra.

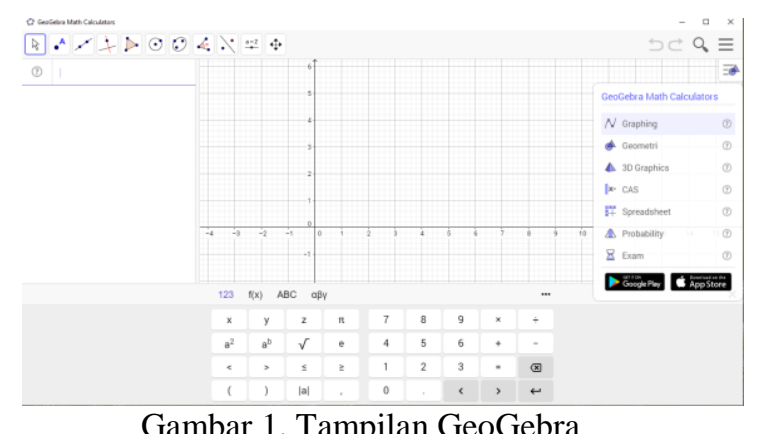

Gambar 1. Tampilan GeoGebra

Sebagai alat untuk menyelesaikan masalah matematika, GeoGebra dengan mudah dipakai untuk menyelesaikan baik masalah aritmatika, aljabar, geometri, statistik maupun kalkulus. Masalah aritmatika bisa diselesaikan dengan memasukkannya pada jendela
Input. Masalah Aljabar dan Kalkulus bisa diselesaikan dengan memanfaatkan perintah-perintah yang disediakan dalam software ini. Masalah geometri diselesaikan dengan memanfaatkan berbagai tool yang tersedia atau dengan menggunakan perintah-perintah yang tersedia. Namun, selain untuk menyelesaikan berbagai masalah matematika, keunggulan lain dari GeoGebra adalah kemampuannya untuk memvisualisasikan konsepkonsep matematika secara dinamik. Keunggulan inilah yang membuat GeoGebra menjadi software yang sangat ampuh untuk membuat media pembelajaran virtual baik untuk matematika maupun pelajaran lain, seperti misalnya fisika.

Media pembelajaran ini bisa dibuat dengan menggunakan berbagai tool maupun perintah yang tersedia, atau dengan mengombinasikannya dengan bahasa pemrograman Javascript. Dengan kemampuan ini GeoGebra bisa diubah menjadi media pembelajaran virtual yang sangat ampuh untuk mengeksplorasi konsep-konsep matematika. Guru dapat memanfaatkan GeoGebra untuk membantu pembuatan konjektur dan pembuktian teorema. Akhirnya yang tak kalah pentingnya (the last but not the least) adalah kemampuan GeoGebra untuk mengekspor file yang dibuatnya menjadi file berekstensi .html yang dinamik. Dengan kemampuan terakhir ini, semua hal yang dikerjakan di GeoGebra bisa ditampilkan di web dengan tanpa kehilangan fitur dinamikanya. Tampilan web tentu saja bisa diakses siswa di mana pun dan kapan pun di dunia ini dengan hanya menggunakan web browser. Konsekuensi lebih lanjut dari hal ini adalah, siswa bisa belajar di mana pun dan kapan pun dengan mengakses media pembelajaran virtual yang sudah dibuat dengan menggunakan GeoGebra. 
Selain fitur-fitur yang sudah disebutkan di atas, fitur lain yang sangat penting dari GeoGebra adalah kemudahan dalam menggunakannya.

\section{METODE PELAKSANAAN}

Metode yang akan dilakukan dalam kegiatan ini adalah melalui beberapa tahap, yaitu observasi langsung, wawancara, presentasi, dan tanya jawab.

Observasi langsung dan wawancara yakni pengabdi langsung datang ke lokasi pengabdian untuk memperoleh data. Hal ini kami lakukan pada saat menjelang maupun saat kegiatan berlangsung. Observasi dan wawancara berguna untuk mengetahui kondisi pembelajaran di SMP Negeri 155 Jakarta dan SMP Uswatun Hasanah, serta menentukan solusi yang akan ditawarkan untuk memecahkan masalah yang ada. Observasi sangat penting untuk mewujudkan kesuksesan kegiatan pengabdian masyarakat itu sendiri.

Pelaksanaan pelatihan kepada guru di sekolah dilakukan dengan menggunakan cara presentasi yang dilakukan oleh nara sumber, yang selanjutnya disertai dengan tanya jawab. Setelah presentasi dan tanya jawab kemudian dilakukan simulasi.

Peserta kegiatan pengabdian masyarakat ini adalah guru-guru Matematika SMPN 155 Jakarta dan SMP Uswatun Hasanah Jakarta.

Pembimbing kegiatan pengabdian masyarakat ini adalah dosen-dosen Universitas Indraprasta PGRI.

Pelaksanaan kegiatan ini dilakukan dalam tiga tahap, yakni tahap persiapan, pelaksanaan dan evaluasi. Tahap pertama adalah tahap persiapan, pada tahap ini tim melakukan survey pendahuluan untuk mengetahui kondisi dengan menganalisis kondisi tempat yang akan digunakan. Pada tahap persiapan, selanjutnya tim menyiapkan bahan materi yang akan diberikan dalam pembekalan atau pelatihan kepada peserta (guru).

Pada tahap kedua yaitu pelaksanaan, dimulai dengan pemberian materi dengan menggunakan slide powerpoint. Metode yang digunakan adalah metode demonstrasi. Peserta (guru) tidak hanya mendengarkan penjelasan yang diberikan, tetapi peserta dapat melihat dan mempraktikkan penggunaan aplikasi GeoGebra dalam pembuatan instrumen.

Dalam selang waktu pemberian materi, tim abdimas melakukan tanya jawab kepada peserta agar terjadi interaksi antara pengabdi dengan peserta (guru). Memberikan beberapa pertanyaan agar peserta (guru) untuk lebih aktif dalam proses pelatihan.

Tahapan yang terakhir adalah tahapan evaluasi, tim abdimas memberikan waktu kepada peserta (guru) untuk mengimplementasikan aplikasi GeoGebra dalam pembuatan media visual pembelajaran matematika berbasis konstruktivisme. Jika masih ada kesulitan, maka tim Abdimas membantu guru agar lebih baik dalam penggunaan aplikasi yang diberikan tersebut.

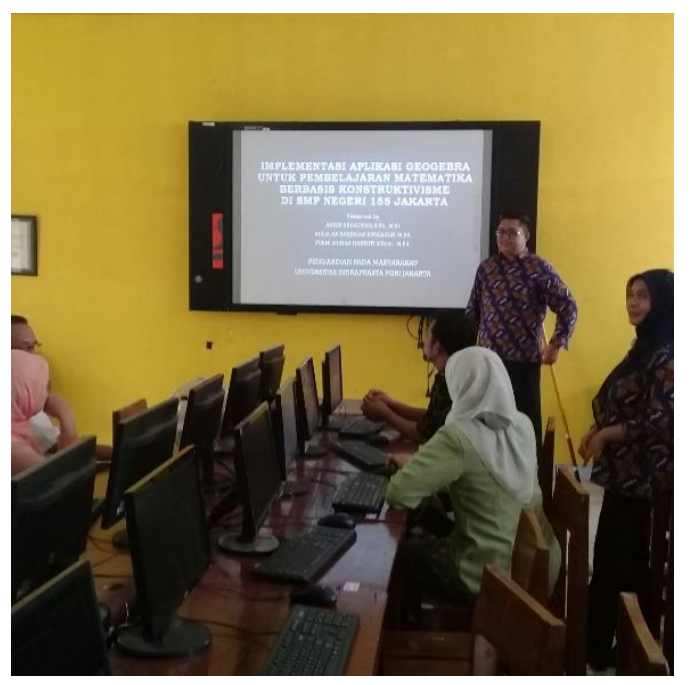



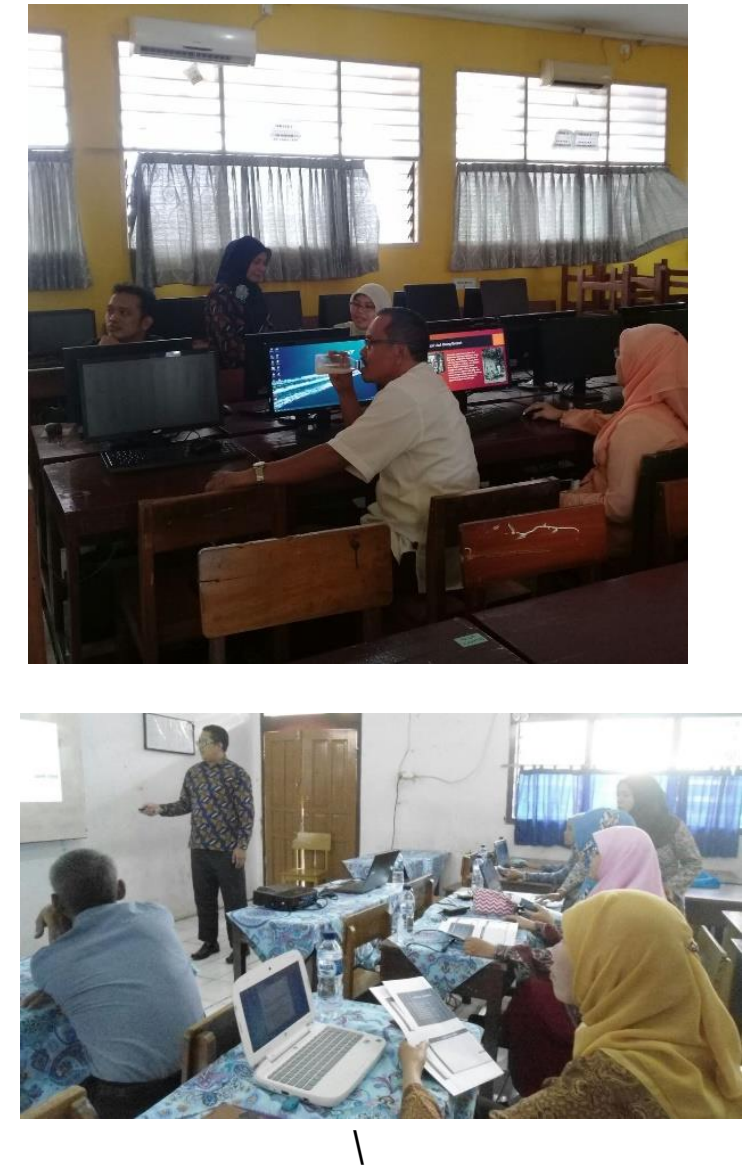

HASIL DAN PEMBAHASAN

Tim pelaksana program pelatihan aplikasi GeoGebra untuk pembelajaran matematika berbasis konstruktivisme ini dilakukan oleh 3 orang dari Universitas Indraprasta PGRI. Lokasi pelatihan dilaksanakan di Ruang Lab Komputer SMPN 155 Jakarta dan Ruang Kelas SMP Uswatun Hasanah. Dipilihnya SMPN 155 Jakarta dan SMP Uswatun Hasanah ini atas dasar beberapa pertimbangan setelah tim pelaksana melakukan observasi di kedua sekolah tersebut. Salah satu alasan adalah belum optimalnya proses pembelajaran matematika yang berkaitan dengan materi aljabar dan geometri di kedua sekolah tersebut. Pada kunjungan pertama, tim pelaksana melakukan kunjungan ke SMPN 155 Jakarta, tim dan kepala SMPN 155 Jakarta membicarakan tujuan, bahan yang akan disampaikan dan menentukan hari pelatihan yang disepakati oleh kedua belah pihak. Pada kunjungan kedua, tim pelaksana melakukan kunjungan ke SMP Uswatun Hasanah, tim dan kepala SMP Uswatun Hasanah membicarakan tujuan, bahan yang akan disampaikan dan menentukan hari pelatihan yang disepakati oleh kedua belah pihak.

Pihak pertama yaitu para guru meminta adanya pelatihan aplikasi GeoGebra untuk pembelajaran matematika khususnya pada materi aljabar dan geometri. Pihak kedua yaitu tim pelaksana memberikan pelatihan aplikasi GeoGebra untuk pembelajaran matematika khususnya pada materi aljabar dan geometri di SMPN 155 Jakarta dan SMP Uswatun Hasanah. Pelatihan tersebut dapat dilaksanakan dengan baik dikarenakan antusias dari para guru kedua sekolah tersebut untuk mengikuti pelatihan serta kerjasama yang baik antara kedua belah pihak.

Berdasarkan pelatihan aplikasi GeoGebra untuk pembelajaran matematika khususnya pada materi aljabar dan geometri di SMPN 155 Jakarta dan SMP Uswatun Hasanah diperoleh hasil sebagai berikut:

1. Guru dapat meningkatkan kualitas proses pembelajaran sesuai dengan ilmu yang diperoleh dalam pelatihan.

2. Guru lebih kreatif dan inovatif dalam menciptakan proses pembelajaran.

3. Guru memiliki pemahaman dan pengetahuan tentang media pembelajaran virtual.

4. Guru dapat menggunakan aplikasi GeoGebra untuk membuat media pembelajaran virtual.

5. Guru dapat membuat media visual, bahan ajar, dan instrumen penilaian yang berkaitan dengan materi aljabar dan geometri.

Evaluasi dari kegiatan pengabdian masyarakat ini terdiri atas sasaran, indikator keberhasilan, dan kendala. 
Sasaran kegiatan pengabdian masyarakat ini adalah

1. Memberikan pengalaman pada guruguru agar lebih kreatif dan inovatif dalam pembelajaran.

2. Pengembangan media pembelajaran visual, bahan ajar, dan instrumen penilaian yang dilakukan oleh guru dalam pelaksanaan proses pembelajaran.

Indikator keberhasilan kegiatan pengabdian masyarakat ini adalah

1. Kemampuan guru dalam menciptakan proses pembelajaran yang kreatif dan inovatif setelah diberikan pelatihan.

2. Guru dapat membuat media pembelajaran visual, bahan ajar, dan instrumen penilaian khususnya yang berkaitan dengan materi aljabar dan geometri.

Kendala yang dialami dalam kegiatan pengabdian masyarakat ini adalah

1. Ada beberapa laptop atau komputer harus diperbaharui terlebih dahulu sistem operasi Windowsnya sehingga membutuhkan waktu yang cukup lama untuk bisa dipasang aplikasi GeoGebra.

2. Ada beberapa laptop atau komputer yang sudah dipasang aplikasi GeoGebra namun tidak semua fitur dalam aplikasi GeoGebra berfungsi khususnya fitur Geometri 3D sehingga tidak dapat digunakan dalam mempelajari materi geometri tiga dimensi.

\section{SIMPULAN}

Pelatihan aplikasi Geogebra untuk pembelajaran matematika di SMPN 155 Jakarta dan SMP Uswatun Hasanah ini telah berjalan sesuai jadwal yang telah disepakati. Berdasarkan tanggapan, respon, dan partisipasi dari para guru, dapat disimpulkan bahwa guru merasa bahwa pelatihan ini sangat bermanfaat bahkan mereka merasa waktu yang diberikan untuk pelatihan ini kurang lama. Guru mampu mengaplikasikan materi yang diperoleh dalam pelatihan sesuai dengan kebutuhannya. Kehadiran para guru pada saat pelatihan di kedua sekolah tersebut sangat antusias. Di samping itu, setelah pelatihan selesai dilakukan, para guru dengan bersemangat ingin mengaplikasikan materi itu pada saat proses pembelajaran karena para guru ingin lebih kreatif dan inovatif dalam menciptakan proses pembelajaran. Selain itu, sebagian guru mengusulkan adanya pelatihan yang lebih lama waktunya dari Tim Pengabdian Masyarakat di kedua sekolah tersebut sehingga materi yang diberikan lebih rinci dan mereka mempunyai kesempatan untuk mempraktikkannya dan bertanya jika ada kesulitan.

Program pelatihan aplikasi GeoGebra untuk pembelajaran matematika di SMPN 155 Jakarta dan SMP Uswatun Hasanah ini sesuai dengan target, sehingga respon positif mengalir dari para peserta pelatihan. Manfaat dari hasil pelatihan telah langsung dapat dirasakan oleh para guru untuk keperluan pengembangan proses pembelajaran yang ada di sekolah. Dengan demikian, diharapkan untuk selanjutnya program pelatihan sejenis atau yang lainnya dapat dikembangkan dan diupayakan keberlanjutannya demi terciptanya pendidikan yang berkualitas, kreatif dan inovatif.

\section{DAFTAR PUSTAKA}

Asri Budiningsih. 2005. Belajar dan Pembelajaran. Jakarta: Rineka Cipta.

Hohenwarter, M., Hohenwarter, J., Kreis, Y., \& Lavicza, Z. (2008). Teaching and Learning Calculus with Free Dynamic Mathematics 
Software GeoGebra. [Online]. Pranasiwi, O., dkk. (2015). Tersedia:

http://www.geogebra.org/publicati

Pengembangan Aplikasi Kunci Determinasi Berbasis Android on s/2008-ICME-TSG16Pokok Bahasan Mamalia di

Calculus-GeoGebra-Paper.pdf [23 SMA/MA. Artikel Ilmiah Maret 2017] Mahasiswa, Vol. 2, No. 1, 1-7. 